\title{
Application of Convolution-deconvolution voltammetry for investigation of 4,4'-bipyridine with benzoquinone derivatives
}

\author{
A.A. Al-Owais ${ }^{1, *}$, I.S. El-Hallag, ${ }^{2, *}$,E.H. El-Mossalamy ${ }^{3}$ \\ ${ }^{1}$ Chemistry Department, Faculty of Science, King Saud University, Riyadh, Sa \\ ${ }^{2}$ Chemistry Department, Faculty of Science, Tanta University, Tanta, Egypt \\ 3 Chemistry Department, Faculty of Science, Benha University, Benha, Egypt \\ *E-mail: aowais@ksu.edu.sa, i.elhallag@yahoo.com
}

Received: 8 July 2021/ Accepted: 9 September 2021 / Published: 10 October 2021

Convolution, deconvolution cyclic voltammetry, chronoamperometric, scanning electron microscopy (SEM) and transmission electron microscopy (TEM) were employed for clarifying the characterization of charge transfer complex (CT) of 4,4'-bipyridine with benzoquinone derivatives. These studies were achieved at a gold electrode in TBAPL/ $\mathrm{CH}_{2} \mathrm{Cl}_{2}$. The kind of the electrode reaction and the kinetic parameters of the CT complex under study were suggested and calculated via the above methods, then confirmed via digital simulation. SEM and TEM were performed for characterization of the structural morphology of the presented complex as well as showing the nanostructured of the complex.

Keywords: Convolution, deconvolution voltammetry, Chronoamperometry, SEM, TEM.

\section{$\underline{\text { FULL TEXT }}$}

(C) 2021 The Authors. Published by ESG (www.electrochemsci.org). This article is an open access article distributed under the terms and conditions of the Creative Commons Attribution license (http://creativecommons.org/licenses/by/4.0/). 